đến chức năng của mắt, nên việc kiểm soát các tổn thương taii mắt rất quan trọng, cần thiết để đánh giá, phát hiện, quản lý bệnh võng mạc đái tháo đường.

Đánh giá chung về tổn thương võng mạc do ĐTÐ cho thấy tỷ lệ bệnh nhân có tổn thương tới $42,8 \%$. So sánh với kết quả nghiên cứu của Orcutt tại Mỹ $(13,9 \%)$, tỷ lệ của chúng tôi cao hơn. Điều này cũng dế hiểu do Mỹ là nước phát triển, điều kiện kinh tế và chăm sóc y tế cao hơn hẳn Việt Nam. Nghiên cứu của Xu (2012) cho thấy tỷ lệ 24,7\% mắc bệnh VMĐTĐ ở người Bắc Kinh. Mặt khác, trong các bệnh nhân mắc bệnh VMĐTĐ, phần lớn còn ở tình trạng tổn thương võng mạc chưa tăng sinh mức độ nhe và vừa (trên $74,2 \%$ ). Tuy nhiên, có $66,1 \%$ bệnh nhân có tình trạng chưa tăng sinh mức độ vừa. Đặc biệt, vẫn có các trường hợp có tăng sinh mức độ nặng rất nặng chiếm $3,2 \%$ số bệnh nhân có tình trạng tổn thương VM tăng sinh. Đây là tình trạng khá nghiêm trọng tổn thương võng mạc, đòi hỏi các biện pháp điều trị chặt chẽ.

Do tình trạng phổ biển của tổn thương võng mạc nên đặt ra yêu cầu sàng lọc sớm nhằm duy trì và giảm thiểu tình trạng tổn thương võng mạc của các bệnh nhân ĐTÐ, đồng thời ngăn ngừa những biến chứng mà bệnh nhân có thể gặp phải, tránh các ảnh hưởng đáng tiếc tới thị lực.

\section{KẾT LUẬN}

1. Bệnh mắt chủ yếu ở người đái tháo đường là đục thủ tinh thể, bệnh lý kết mạc, bệnh lý giác mạc, bệnh lý võng mạc.

2. Tổn thương võng mạc do đái tháo đường tương đương ở 2 mắt; trong đó chủ yếu là bệnh VMĐTĐ chưa tăng sinh thể vừa và nhe chiếm $74,2 \%$, có $22,6 \%$ thể nặng và rất nặng.

\section{TÀI LIÊU THAM KHẢO}

1. Ta Văn Bình (2006). Bệnh đái tháo đường - Tăng glúcose máu. Nhà xuât bản Y học, Hà Nội, 45-76.

2. W. H. Organization.( 2020), "Strengthening diagnosis and treatment of Diabetic Retinopathy in SEA Region,".

3. R. Lee, T. Y. Wong, and C. Sabanayagam.( 2015), "Epidemiology of diabetic retinopathy, diabetic macular edema and related vision loss," (in eng), Eye Vis (Lond), vol. 2, p. 17.

4. M. V.' Van Hecke et al.( 2005), "Diabetic retinopathy is associated with mortality and cardiovascular disease incidence: the EURODIAB prospective complications study," vol. 28, no. 6, pp. 1383-1389.

5. J. W. Yau et al.( 2012), "Global prevalence and major risk factors of diabetic retinopathy," vol. 35, no. 3, pp. 556-564.

6. N. T. T. Thủy, T. A. Tuấn, and D. T. Bình.( 2009), "Khảo sát biến chứng tai mắt trên bênh nhân đái tháo đường điều trị tại Bệnh viện Đại học y dược TP. Hồ Chí Minh," Tạp chí Ỳ học TP. Hồ Chí Minh, vol. 13, pp. 86 - 91.

7. P. V. Priya, A. Srinivasarao, and J. J. I. J. S. I. T. Sharma.(2013), "Diabetic Retinopathy-Can Lead To Complete Blindness," vol. 2, no. 4, pp. 254-265.

8. H. A. Kahn and R. J. A. j. o. o. Hiller.(1974), "Blindness caused by diabetic retinopathy," vol. 78, no. 1 , pp. 58-67.

\title{
MỐI LIÊN QUAN GIỮA SỨC KHOẺ RĂNG MIÊNG VớI CHẤT LƯợNG CUộC SỐNG Ở NGƯỜI CAO TUỔI TİNH BÌNH DƯƠNG
}

\section{TÓM TẮT}

Mục tiêu nghiên cứu nhằm tìm hiểu mối liên quan giữa bệnh sâu răng, viêm quanh và tình trạng mất răng với chất lượng cuộc sống ở người cao tuối (NCT) ở tình Bình Dương. Đối tượng nghiên cứu là người cao tuổi (> 60 tuổi) của tỉnh Bình Dương. Phương pháp nghiên cứu: mô tả cắt ngang thực hiện trến 1350 NCT. Kết quả cho thây điểm OHIP

\footnotetext{
${ }^{1}$ Bệnh viện Răng Hàm Mặt Trung Uơng Hà Nội 2Phòng khám nha khoa thẩm mỹ Phương Đông 3 Viện DT Răng Hàm Mặt, Trướng Đại Học Y Hà Nội Chịu trách nhiệm chính: Võ Thị Thuý Hồng Email: vothuyhong71@yahoo.com Ngày nhận bài: 22.10.2021 Ngày phản biện khoa học: 21.12.2021 Ngày duyệt bài: 29.12.2021
}

14VN nhóm mất răng: 7,64 điểm (so với nhóm mất răng: 6,92 điểm); OR: 2,42 (CI 95\%: 1,29 - 4,56). Điểm OHIP 14VN nhóm NCT bi VQR là 8,15 điểm (so với nhóm không bị VQR 7,35 điểm); OR 1,52 (CI 95\%: $1,1-2,1)$. Điển OHIP 14VN nhóm có dưới 3 VLPLM là 7,82 điểm (so với 5,28 điểm); OR 2,62 (CI 95\% 1,31$5,24)$. Kết luân: Bệnh sâu rằng, viêm quanh răng và tình trạng mất răng gây ảnh hưởng tới chất lượng cuộc sổng của người cao tuổi tỉnh Bình Dương.

Tư khoá: sẩu răng, viêm quanh răng, mất răng, chất lượng cuộc sống.

\section{SUMMARY \\ ASSOCIATION OF ORAL HEALTH AND LIFE QUALITY OF ELDERLY PEOPLE IN BINH DUONG PROVINCE}

Abstract: The objective of the study was to find out the associations between caries, periodontitis and 
tooth loss with quality of life in elderly people in Binh Duong province. Research subjects are elderly people (> 60 years old) of Binh Duong province. Method: cross-sectional description performed on 1350 elderly. The results showed that the score of OHIP-14VN in the tooth loss group: 7.64 points (compared with the missing teeth group: 6.92 points); OR: 2.42 (95\% CI: $1.29-4.56)$. The score of OHIP-14VN for the elderly group with VQR is 8.15 points (compared with the group without periodontitis at 7.35 points); OR 1.52 (95\% CI: 1.1-2.1). In the OHIP 14VN dictionary, the group with less than 3 healthy sextants is 7.82 points (compared to 5.28 points); OR 2.62 (95\% CI 1.315.24). Conclusion: Dental caries, periodontitis and tooth loss associated the quality of life of the elderly in Binh Duong province. of life.

Keywords: caries, periodontitis, tooth loss, quality

\section{I. ĐĂT VẤN ĐỀ}

Hiện nay các nhà khoa học dần nhận ra những hạn chế khi chỉ đánh giá mặt lâm sàng của tình trạng bệnh lý răng miệng, các chỉ số lâm sàng của bệnh răng miệng như sâu răng, nha chu chưa nểu bât được các khái niêm của WHO về sức khỏe, đặc biệt là khía cạnh khỏe mạnh về mă̆t tinh thần, xã hội và hành vi sức khỏe.[1], [2] Chất lượng cuộc sống sức khoẻ răng miêeng (CLCS-SKRM) đang được xác định là lĩnh vực sức khỏe ưu tiên trong bối cảnh các vấn đề chất lượng cuộc sống đi đầu trong các chính sách y tế công cộng. [2] Ở nước ta trong những năm gần đây, chất lượng cuộc sống đang ngày càng được nâng cao, cùng với đó tuổi thọ trung bình của người dân cũng tăng lên, và số lượng người cao tuổi cũng tăng cao trong cộng đồng dân số. Trong khi các bệnh răng miệng ở người cao tuổi liên quan mật thiết đến quá trình thoái hóa của cơ thể và thói quen vệ sinh răng miệng với tỷ lệ tăng cao của các bệnh lý như, sâu răng, mất răng, bệnh lý nha chu, loạn năng khớp thái dương hàm, chứng khô miệng và bệnh ung thư miệng. [3] Các nghiên cứu trong nước và thế giới đã chỉ ra rằng: Sâu răng và bệnh quanh răng vẫn là hai bệnh phổ biến có tỷ lệ và số trung bình mắc rất cao ở những người còn răng và được coi là những nguyên nhân chính dẫn tới mất rắng...[1],[3] Các nghiên cứu về chất lượng cuộc sống liên quan sức khỏe răng miệng tại Việt
Nam còn chưa nhiều và cũng mới chỉ được quan tâm trong vài năm trở lại đây. Xuất phát từ thực tế trên, chúng tôi tiến hành thực hiện nghiên cứu: "Mối liên quan giữa sức khoẻ răng miệng với chất lượng cuộc sống ở người cao tuổi tình Bình Dương". Mục tiêu nghiên cứu nhằm tìm hiểu mối liên quan giữa bệnh sâu răng, viêm quanh và tình trang mất răng với chất lượng cuộc sống ở người cao tuổi ở tình Bình Dương.

\section{II. ĐỐI TƯợNG VÀ PHƯƠNG PHÁP NGHIÊN CỨU}

2.1 Thời gian và địa điểm nghiên cứu: từ tháng 09/2015 đến tháng 09/2016 tại tỉnh Bình Dương

2.2 Đối tượng nghiên cứu: Là người cao tuổi (> 60 tuổi) của tỉnh Bình Dương, đồng ý tự nguyên tham gia nghiên cứu. Loại trừ những người không đồng ý tham gia nghiên cứu; không có mặt trong khi điều tra, sinh sống tạm thời trong thời gian ngắn ở địa bàn điêu tra; không đủ năng lực trả lời khi thăm khám.

2.3 Phương pháp nghiên cứu: mô tả cắt ngang

Cõ̃ mẫu trong nghiên cứu này được tính theo công thức:

Trong đó:

$$
n=Z_{1-\alpha / 2}^{2} \times \frac{p(1-p)}{d^{2}} \times D E
$$

n: Cõ̃ mẫu nghiên cứu cần có.

p: Tỉ lệ sâu răng ở người cao tuổi tại Hà Nội năm 2004, $p=55 \%$ [3]

d: Mức chính xác tuyệt đối (lấy $d=0,033$ )

a: Mức ý nghĩa thống kê; lây $a=0,05$, nên $\mathrm{Z}_{1-\mathrm{a} / 2}=1,96$

DE: Do sử dụng kỹ thuật chọn mẫu 30 chùm ngẫu nhiên nên cỡ mấu cần nhẩn với hệ số thiết kế mẫu (lấy $D E=1,5$ ).

Áp dụng công thức cỡ mẫu cần có là 1310 người, thực tế tiến hành trên 1350 NCT.

Cách chọn mẫu: chọn mẫu chùm ngẫu nhiên

\section{Các chỉ số nghiên cứu}

*Chỉ số răng sâu, mất và trám SMT (WHO, 1997); Chỉ số Quanh răng cộng đồng CPI (Community Periodontal Index)

Sử dụng bộ câu hỏi OHIP14-VN, gồm 14 câu hỏi chia thành 7 lĩnh vực.

\section{Bảng 2.4: Định nghĩa và phân loại các câu hỏi phỏng vấn OHIP14-VN. [2]}

\begin{tabular}{|c|c|c|}
\hline Lĩnh vực tác động & STT câu hỏi PV & Định nghĩa \\
\hline \multirow{2}{*}{ Giới hạn chức năng } & 1 & Cảm thấy khó khăn khi phát âm \\
\cline { 2 - 3 } & 2 & Cảm thấy vị giác bị kém đi \\
\hline \multirow{2}{*}{ Đau thực thể } & 3 & Cảm thấy đau hay khó chịu trong miệng \\
\cline { 2 - 3 } & 4 & Cảm thấykhó chịu khi ăn bất kỳ loại thức ăn nào \\
\hline \multirow{2}{*}{ Không thoải mái tâm lý } & 5 & Cảm thấy tự ti \\
\hline
\end{tabular}




\begin{tabular}{|c|c|c|}
\hline & 6 & Cảm thấy căng thằng \\
\hline \multirow[t]{2}{*}{ Hạn chễ thể chất } & 7 & $\begin{array}{c}\text { Cảm thấy chế độ ăn của mình không đủ tốt hay không thể } \\
\text { chấp nhận }\end{array}$ \\
\hline & 8 & Phải tạm ngưng bữa ăn \\
\hline \multirow{2}{*}{ Hạn chế tâm lý } & 9 & Cảm thấy khó thư giãn \\
\hline & 10 & Cảm thấy bối rối \\
\hline \multirow{2}{*}{ Hạn chế xã hội } & 11 & Cảm thẫy dễ cáu gắt, dễ phiên lòng với người khác \\
\hline & 12 & Cảm thấy khó khăn khi làm những việc thông thường \\
\hline \multirow{2}{*}{ Tàn tật } & 13 & Cảm thấy cuộc sống nói chung bị kém đi \\
\hline & 14 & Tiưng hoàn toàn không thể làm được việc như mong muốn \\
\hline
\end{tabular}

*Cách tính điểm CLCS-SKRM dựa theo OHIP-14VN. Sử dụng thang đo Likert 5 mức độ để đánh giá tần suất các hoạt động bị ảnh hưởng bởi tình trạng SKRM trong 1 năm qua: 0 chưa bao giờ; 1 - hiếm khi; 2 - Thỉnh thoảng; 3 Thường xuyên; 4 - rất thường xuyên.

Điểm đánh giá cho mỗi câu hỏi là $0-4$, cho mỗi lînh vực (gồm 2 câu hỏi) là $0-8$ và tổng điểm OHIP-14 cho 14 câu hỏi ở mỗi người sẽ dao dộng từ 0 đến 56 điểm. Điểm càng cao cho thây chất lượng cuộc sống bị ảnh hưởng càng nhiều bởi sức khỏe rằng miệng.

Xử lý và phân tích số liệu: Nhập số liệu sử III. KẾT QUẢ NGHIÊN CứU

Bảng 1: Phân bố điểm trung bình OHIP-14VN của NCT

\begin{tabular}{|c|c|c|c|c|c|}
\hline \multicolumn{2}{|c|}{ Khía canh $\quad$ Điếm trung bình OHIP } & \multirow{2}{*}{$\begin{array}{c}\begin{array}{c}\text { Trung } \\
\text { bình }\end{array} \\
1,2 \\
\end{array}$} & \multirow{2}{*}{ 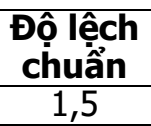 } & \multirow{2}{*}{$\begin{array}{c}\text { Giá trị } \\
\text { nhó nhất } \\
0\end{array}$} & \multirow{2}{*}{$\begin{array}{c}\begin{array}{c}\text { Giá tri } \\
\text { Iớn nhất }\end{array} \\
7\end{array}$} \\
\hline Giới hạn chức năng & 1350 & & & & \\
\hline Khó khăn phát âm & 1350 & 0,4 & 0,8 & 0 & 4 \\
\hline Cảm thấy vị giác kém đi & 1350 & 0,7 & 0,9 & 0 & 4 \\
\hline Đau thực thế & 1350 & 1,9 & 1,9 & 0 & 8 \\
\hline Đau hay khó chịu trong miệng & 1350 & 0,9 & 1,0 & 0 & 4 \\
\hline Cảm thấy khó chịu khi ăn & 1350 & 0,9 & 1,0 & 0 & 4 \\
\hline Không thoải mái tâm lý & 1350 & 1,0 & 1,6 & 0 & 8 \\
\hline Tự ti & 1350 & 0,5 & 0,9 & 0 & 4 \\
\hline Cảm thấy căng thắng & 1350 & 0,5 & 0,8 & 0 & 4 \\
\hline Han chế vêt thế chất & 1350 & 1,2 & 1,6 & 0 & 7 \\
\hline Vấn đề ăn uống không vừa ý & 1350 & 0,6 & 0,9 & 0 & 4 \\
\hline Tạm ngưng bữa ăn & 1350 & 0,6 & 0,9 & 0 & 4 \\
\hline Hạn chế về tâm lý & 1350 & 0,8 & 1,5 & 0 & 6 \\
\hline Cảm thấy khó thư giẫn & 1350 & 0,4 & 0,8 & 0 & 4 \\
\hline Cảm thấy bối rối & 1350 & 0,4 & 0,8 & 0 & 3 \\
\hline Hạn chế về xã hội & 1350 & 0,7 & 1,3 & 0 & 6 \\
\hline Dê cáu gắt & 1350 & 0,4 & 0,7 & 0 & 4 \\
\hline Khó làm những việc thông thường & 1350 & 0,4 & 0,7 & 0 & 3 \\
\hline Tàn tật & 1350 & 0,8 & 1,3 & 0 & 6 \\
\hline Cảm thấy cuộc sổng bị kém đi & 1350 & 0,5 & 0,8 & 0 & 3 \\
\hline Không thế làm việc như mong muốn & 1350 & 0,3 & 0,6 & 0 & 3 \\
\hline Tống & 1350 & 7,6 & 8,9 & 0 & 42 \\
\hline
\end{tabular}

Nhận xét: Điểm trung bình tác động sức khỏe răng miệng lên chất lượng cuộc sống OHIP-14VN trong nhóm nghiên cứu là $7,6 \pm 8,9$. Trong đó lĩnh vực đau thực thể bị tác động nhiều nhất với 1,9 điểm, tiếp theo là hạn chế về chức năng và hạn chế về thể chất (1,2 điểm). Hạn chế về xã hội là lính vực bị tác động ít nhất với 0,7 điểm. dụng phần mềm Epi Data 3.1. Phân tích số liệu được thực hiện với phần mềm SPSS 16.0. Sử dụng kiểm định Mann-Whitney và Kruskal-wallis để so sánh sự khác biệt về giá trị trung bình. Sử dụng kiểm định Chi-square hoặc Fisher để so sánh sự khác biệt về tỷ lệ.

Đạo đức trong nghiên cứu: Người tham gia nghiên cứu tự nguyện đồng ý tham gia nghiên cứu. Mọi thông tin thu thập được đảm bảo bí mật cho đối tượng lựa chọn, chỉ phục vụ cho mục đích nghiên cứu. Nghiên cứu được sự đồng ý và phê duyệt của địa phương và các cấp lãnh đạo có liên quan. 
Bảng 2: Điểm trung bình OHIP trên 7 lĩnh vực theo tình trạng sâu răng

\begin{tabular}{|c|c|c|c|}
\hline Khía cạnh & $\begin{array}{c}\text { Khống sấm TB OHIP } \\
\text { TB (ĐLC) }\end{array}$ & $\begin{array}{c}\text { Có sâu } \\
\text { TB (ĐLC }\end{array}$ & p \\
\hline Giới hạn chức năng & $1,11(1,53)$ & $1,25(1,5)$ & $\mathbf{0 , 1 0 7}$ \\
\hline Đauu thực thế & $1,92(1,94)$ & $1,72(1,76)$ & 0,076 \\
\hline Không thoải mái tâm lý & $1,05(1,58)$ & $1,04(1,54)$ & 0,912 \\
\hline Hạn chế thế chất & $1,21(1,64)$ & $1,03(1,48)$ & 0,058 \\
\hline Hạn chế tâm lý & $0,86(1,50)$ & $0,80(1,41)$ & 0,459 \\
\hline Hạn chế xã hội & $0,72(1,33)$ & $0,71(1,30)$ & 0,901 \\
\hline Tàn tật & $0,77(1,33)$ & $0,79(1,34)$ & 0,819 \\
\hline Tống & $\mathbf{7 , 6 5 ( 9 , 0 1 )}$ & $\mathbf{7 , 3 5 ( 8 , 7 1 )}$ & $\mathbf{0 , 5 7 2}$ \\
\hline
\end{tabular}

Mann-Whitney test

Nhận xét: Kết quả cho thây, điểm trung bình trên cả 7 lĩnh vực của hai nhóm không bị sâu răng với nhóm hiện mắc sâu răng không có sự khác biệt có ý nghĩa thống kê.

Bảng 3: Phân bố điểm trung binh OHIP-14VN trên 7 lĩnh vực theo tình trạng quanh răng

\begin{tabular}{|c|c|c|c|}
\hline Khía cạnh Điếm trung bình & $\begin{array}{c}\text { Đủ 3 vùng LPLM } \\
\text { TB (ĐLC) }\end{array}$ & $\begin{array}{c}\text { Không đủ } \mathbf{3} \text { vùng } \\
\text { LPLM TB (ĐLC)) }\end{array}$ & p \\
\hline Giới hạn chức năng & $0,83(1,25)$ & $1,19(1,56)$ & 0,009 \\
\hline Dau thực thế & $1,53(1,69)$ & $1,90(1,91)$ & 0,030 \\
\hline Không thoải mái tâm lý & $0,69(1,32)$ & $1,08(1,59)$ & 0,005 \\
\hline Hạn chế thế chất & $0,81(1,26)$ & $1,19(1,63)$ & 0,008 \\
\hline Hạn chế tâm lý & $0,53(1,17)$ & $0,88(1,50)$ & 0,008 \\
\hline Hạn chế xã hội & $0,40(1,04)$ & $0,75(1,35)$ & 0,003 \\
\hline Tàn tật & $0,47(1,03)$ & $0,82(1,37)$ & 0,005 \\
\hline Tống & $5,28(7,25)$ & $7,82(9,05)$ & 0,001 \\
\hline
\end{tabular}

Mann-Whitney test

Nhận xét: Kêt quả cho thấy, nhóm NCT có dưới 3 vùng lục phân lành mạnh có tổng điểm ohip trung bình cao hơn nhóm NCT có nhiều hơn 3 vùng lục phân lành mạnh. Trên tất cả 7 khía cạnh của CLCS bị ảnh hưởng bởi SKRM, nhóm có dưới 3 vùng lục phân lành mạnh cũng đều bị ảnh hưởng nhiều hơn. Kết quả có ý nghĩa thống kê với $p<0,05$.

Bảng 4: Tông điêm trung binh OHIP-14VN theo tình trạng bệnh lý

\begin{tabular}{|c|c|c|c|c|}
\hline \multicolumn{2}{|r|}{ Trung bình OHIP } & Trung bình & Lệch chuẩn & $\mathbf{p}$ \\
\hline \multirow{2}{*}{ Sâu răng } & Không sâu răng & 7,65 & 9,01 & \multirow{2}{*}{0,572} \\
\hline & Sâu răng & 7,35 & 8,71 & \\
\hline \multirow{2}{*}{ Trám răng } & Không trám răng & 7,55 & 8,87 & \multirow{2}{*}{0,871} \\
\hline & Trám răng & 7,80 & 10,75 & \\
\hline \multirow[b]{2}{*}{ Mất răng } & Không mất răng & 6,92 & 8,44 & \multirow[b]{2}{*}{0,343} \\
\hline & Mất răng & 7,64 & 8,98 & \\
\hline \multirow{2}{*}{ SMT-R } & $\mathrm{SMT}=0$ & 6,5 & 8,2 & \multirow{2}{*}{0,222} \\
\hline & $\mathrm{SMT}>0$ & 7,6 & 9,0 & \\
\hline \multirow{2}{*}{ Phục hình } & Không có PH & 7,76 & 8,99 & \multirow{2}{*}{0,228} \\
\hline & Có PH & 7,10 & 8,83 & \\
\hline \multirow{2}{*}{ Nhu cầu PH } & Không có NCPH & 6,18 & 8,08 & \multirow{2}{*}{0,001} \\
\hline & Có NCPH & 8,03 & 9,17 & \\
\hline \multirow{2}{*}{ VQR } & $\mathrm{CPI} \leq 2$ & 7,35 & 9,00 & \multirow{2}{*}{0,145} \\
\hline & CPI $>2$ & 8,15 & 9,0 & \\
\hline \multirow{2}{*}{ Số vùng LPLM } & $>3$ vùng & 5,28 & 7,25 & \multirow{2}{*}{0,001} \\
\hline & $<3$ vùng & 7,82 & 9,05 & \\
\hline
\end{tabular}

Mann-Whitney test

Nhận xét: Không có sự khác biệt về tổng điểm OHIP-14VN trung bình giữa những NCT hiện có và không có thương tổn sâu răng, tương tự không có sự khác biệt giữa nhóm NCT có

trám và không trám răng với $p>0,05$

CLCS-SKRM của nhóm không mất răng, SMT $=0$ cao hơn rõ rệt so với nhóm còn lại nhưng chưa có ý nghĩa thống kê. 
Nhóm NCT có nhu cầu phục hình có tổng điểm OHIP-14VN cao hơn nhóm không có NCPH với $p=0,001$

Về thương tổn nha chu, nhóm NCT có dưới 3 vùng LPLM có CLCS thấp hơn có ý nghĩa thống kê so với nhóm còn nhiều hơn 3 vùng LPLM với $\mathrm{p}=0,001$.

Nhóm có túi quanh răng có CLCS thấp hơn nhóm không có túi quanh răng với $p=0,145$.

Bảng 5: Độ lớn môi liên quan giữa các chỉ số lâm sàng với OHIP 14VN

\begin{tabular}{|c|c|c|c|}
\hline Chỉ số & $\begin{array}{l}\text { Không tác động } \\
\text { thường xuyên/rất } \\
\text { thường xuyên }\end{array}$ & $\begin{array}{c}\text { Tác động } \\
\text { thường xuyên/ rất } \\
\text { thường xuyên }\end{array}$ & $\begin{array}{l}\text { OR } \\
(\mathrm{CI} \\
95 \%)\end{array}$ \\
\hline Không sâu răng & $782(85,3)$ & $135(14,7)$ & 1 \\
\hline Sâu răng & $373(86,1)$ & $60(13,9)$ & $0,93(0,67-1,29)$ \\
\hline Không trám răng & $1126(85,6)$ & $189(14,4)$ & 1 \\
\hline Trám răng & $29(82,9)$ & $6(17,1)$ & $1,23(0,51-3,01)$ \\
\hline Không mất răng & $146(93,0)$ & $11(7,0)$ & 1 \\
\hline Mất răng & $1009(84,6)$ & $184(15,4)$ & $2,42(1,29-4,56)$ \\
\hline SMT $=0$ & $95(93,1)$ & $7(6,9)$ & 1 \\
\hline SMT>0 & $1060(84,9)$ & $188(15,1)$ & $2,41(1,10-5,27)$ \\
\hline Không có NCPH & $309(90,9)$ & $31(9,1)$ & 1 \\
\hline Có NCPH & $836(83,9)$ & $161(16,1)$ & $\mathbf{1 , 9 2}(1,28-2,88)$ \\
\hline Không có PH & $827(85,4)$ & $141(14,6)$ & 1 \\
\hline Có PH & $308(85,6)$ & $52(14,4)$ & $0,99(0,70-1,40)$ \\
\hline CPI $\leq 2$ & $864(87,0)$ & $129(13,0)$ & 1 \\
\hline CPI $>2$ & $291(81,5)$ & $66(18,5)$ & $\mathbf{1}, \mathbf{5 2}(1,10-2,10)$ \\
\hline$>3$ vùng LPLM & $130(93,5)$ & $9(6,5)$ & 1 \\
\hline$<3$ vùng LPLM & $1025(84,6)$ & $186(15,4)$ & $2,62(1,31-5,24)$ \\
\hline
\end{tabular}

Chi-square test

Nhận xét: Nhóm NCT bị mất răng có CLCS bị ảnh hưởng thường xuyên/rất thường xuyên bởi SKRM cao gấp 2,42 lần nhóm NCT không mất răng $(p=0,002)$; nhóm có $S M T>0$ bị ảnh hưởng gấp 2,41 lần nhóm có chỉ số SMT $=0 \quad(p=0,027)$. Không có sự khác biệt có ý nghĩa về ảnh hưởng của SKRM giữa nhóm có sâu răng hay không và có trám răng hay không.

Nhóm NCT có từ 3 vùng LPLM trở lên ít bị ảnh hưởng bởi SKRM hơn 1/2,62 lần so với nhóm có ít hơn 3 vùng $L P L M$ với $p=0,003$. Về độ nặng của tổn thương mô nha chu, nhóm có túi lợi nông (CPI nặng nhất >2) có nguy cơ bị ảnh hưởng thường xuyên/rất thường xuyên cao gấp 1,52 lần nhóm không có túi lợi nông, kết quả có ý nghĩa thống kê với $p=0,014$.

\section{BÀN LUÂ̂N}

Đo lường các vấn đề răng miệng ảnh hưởng đến CLCS là một phần quan trọng trong việc đánh giá sức khỏe răng miệng. Sức khỏe không chỉ đánh giá dựa vào tình trạng ốm đau, bệnh tật, ảnh hưởng xã hội mà còn đánh giá sức khỏe về cả khía cạnh chức năng, tâm lý và xã hội. Chính vì vậy, nghiên cứu của chúng tôi đã chọn chỉ số OHIP-14, là một trong những phương pháp phổ biến và hiệu quả đánh giá ảnh hưởng của các vấn đề răng miệng đến chất lượng cuộc sống của NCT, bởi tính đơn giản dễ áp dụng đặc biệt trên đối tượng NCT. Bảng 1 điểm trung bình tác động sức khỏe răng miệng lên chất lượng cuộc sống OHIP-14 trong nhóm nghiên cứu là $7,6 \pm 8,9$. Kết quả này thấp hơn so với nghiên cứu của Silva và cộng sự tại Brazil $(9,1 \pm 10,6)$, Rodakowska tại Đông Bắc Phần Lan $(17,6 \pm$ 14,3), Inukai $M$ tại Nhật Bản $(13 \pm 9,1)$ và Ulinski tại Brazil $(9,1 \pm 9,47)$, cho thấy CLCS liên quan SKRM của NCT tại địa bàn cao hơn các nghiên cứu này. [6],[7],[8] Tại nước ta, vấn đề chất lượng cuộc sống còn khá mới mẻ, NCT thường có xu hướng chịu đưng và chấp nhận nhiêu hơn về tuổi già với các phiền toái do sức khỏe răng miệng gây ra do yếu tố văn hóa cộng với điều kiện kinh tế và bảo trợ y tế về vấn đề răng miệng còn thấp nên đã gián tiếp làm giảm tác động của SKRM lên CLCS của NCT.

Qua bảng 2 có thể thây điểm trung bình chỉ số OHIP-14 trên cả 7 lĩnh vực của hai nhóm không bị sâu răng với nhóm hiện mắc sâu răng không có sự khác biệt. Có nghĩa là những tổn thương sâu răng hiện tại chưa tác động làm ảnh hưởng đến CLCS của NCT. Điều này có thể được giải thích do tổn thương sâu răng ở người già thường tiến triển chậm với triệu chứng cơ năng nghèo nàn, chưa ảnh hưởng đến CLCS một cách rõ rệt đủ để NCT quan tâm. Điều này cũng giải 
thích tình trạng bỏ sót không điều trị phuc hồi khi sâu răng ở giai đoạn sớm dẫn đến tỷ lệ mất răng cao do sâu ở NCT. Chỉ đến khi mất răng do sâu, NCT mới bắt đầu cảm thấy bị ảnh hưởng bởi vấn đề răng miệng.

Bảng 4 cho thấy tổng điểm trung bình OHIP14VN ở nhóm NCT có mất răng là 7,64 điểm cao hơn không có ý nghĩa thống kê so với nhóm không mất răng $(6,92$ điểm). Kết quả chưa có ý nghĩa thống kế nhưng tương đồng các nghiên cứu của Nguyễn Thị Sen ( 9,5 điểm và 8,3 điểm). [1] Tương tự, nhóm có chỉ số SMT>0 cũng có tổng điểm trung bình OHIP cao hơn không có ý nghĩa thống kê so với nhóm có chỉ số $\mathrm{SMT}=0$ (7,6 và 6,5 điểm, bảng 3$)$. Kết quả ở bảng 5 cho thấy nhóm có mất răng có CLCS bi ảnh hưởng với tần suất thường xuyên và rất thường xuyên bởi vấn đề răng miệng cao hơn gấp 2,42 lần so với nhóm không mất răng (OR: 2,42,95\% CI: 1,29-4,56); nhóm có chỉ số SMT >0 bi ảnh hưởng thường xuyên và rất thường xuyên gấp 2,41 lần so với nhóm có $S M T=0$. Kết quả có ý nghĩa thống kê với $p$ lần lượt bằng 0,002 và 0,027 . Như vậy, mất răng gây khó khăn trong vấn đề ăn nhai, phát âm, thẩm mỹ và những hệ lụy khác là nhân tố quan trọng ảnh hưởng đến chất lượng cuộc sống ở NCT.

Nhóm NCT có phục hình trong miệng có tổng điểm trung bình theo OHIP là 7,1 điểm thấp hơn nhóm không được làm phục hình 7,76 $(p=0,228)$, sự khác biệt không có ý nghĩa thống kê (bảng 4). Nhưng ở bảng 5 thì cho thây nhóm NCT có phục hình trong miệng có tỷ lê người có CLCS bị ảnh hưởng thường xuyên/rất thường xuyên bằng 0,99 lần nhóm không có phục hình trong miệng (OR: 0,99, 95\% CI: 0,70-1,40), kết quả trên không thấy có ý nghĩa thống kê với $p=0,92$ (bảng 5 ). Điêu này cho thấy nhóm có phục hình trong miệng không có CLCS khác biệt rõ rệt với nhóm còn lại, có thể do chất lượng phục hình chưa đảm bảo hoặc những phục hình cũ hiện không còn phù hợp do mất răng tăng thêm hay do sự biến đổi ở sống hàm mất răng và nhiều yếu tố khách quan khác. Kết quả này cũng tương tự với nghiên cứu của Ulinski ở Brazil, nhóm có phục hình bị ảnh hưởng nhiều gấp 1,22 lần nhóm không có phục hình (với $\mathrm{CI}$ : 0,9-1,65)[8] Để đánh giá sâu hơn về ảnh hưởng mất răng (hậu quả của sâu răng, bệnh quanh răng) đến CLCS, chúng tôi đánh giá đến chỉ số nhu cầu phục hình của nhóm đối tượng nghiên cứu. Kết quả cho thây nhóm có nhu cầu phục hình răng có tổng điểm trung bình OHIP cao hởn hẳn nhóm không có nhu cầu phục hình $(8,03$ điểm với 6,18 điểm) với $p=0,001$ (bảng 4); đồng thời tỷ lệ gặp tác động thường xuyên/rất thường xuyên đến CLCS ở nhóm có nhu câu phục hình cũng cao hơn gấp 1,92 lần (OR: 1,92, 95\% $\mathrm{CI}: 1,28-2,88)$ với $\mathrm{p}=0,001$ (bảng 5 ). Nghiên cứu của Ulinski cũng cho thấy kết quả tương tự $(\mathrm{OR}=1,16)$ mặc dù chưa có ý nghĩa thống kê. [8]

Kết quả tại bảng 3 cho thấy, nhóm NCT có dưới 3 vùng lục phân lành mạnh có tổng điểm OHIP trung bình 7,82 điểm cao hơn nhóm NCT có từ 3 vùng lục phân lành mạnh trở lên 5,28 điểm, sự khác biệt có ý nghĩa thống kê với $\mathrm{p}=0,001$. Trên tất cả 7 khía cạnh của CLCS bị ảnh hưởng bởi SKRM, nhóm có dưới 3 vùng lục phân lành mạnh cũng đều bị ảnh hưởng nhiều hơn, kết quả có ý nghĩa thống kê với $\mathrm{p}<0,05$. Bảng 5 cho thấy rằng, nhóm NCT có từ 3 vùng LPLM trở lên ít bị ảnh hưởng thường xuyên/rất thường xuyên bởi SKRM theo tỉ lệ $1 / 2,62$ lần so với nhóm có ít hơn 3 vùng LPLM, tuy nhiên sự khác biệt không có ý nghĩa thống kê với $\mathrm{p}=0,003$. Như vậy số vùng lục phân có mô nha chu bị tổn thương càng nhiều sẽ ảnh hưởng càng lớn và rõ rệt đến cuộc sống của NCT.

Nhóm có túi lợi (CPI nặng nhất >2) cũng có nguy cơ bị ảnh hưởng thường xuyên/rất thường xuyên bởi SKRM cao gấp 1,52 lần nhóm không có túi lợi (Or: 1,52,95\% CI: 1,10-2,10), kết quả có ý nghĩa thống kê với $p=0,014$ (bảng 5). Kết quả của chúng tôi tương đồng với nghiên cứu của Bernabe nghiên cứu trên 3122 người lớn tuổi ở Anh khẳng định, bênh nha chu có liên quan với số điểm OHIP-14 (OR: 1,26, 95\% CI: 1,16-1,38), độc lập với các đặc điểm nhân khẩu học, xã hội và các bệnh lý răng miệng khác. [4] Nghiên cứu của Needleman và cộng sư cũng cho thấy rằng bênh quanh răng có ảnh hưởng tiêu cực đễn chất lượng cuộc sống với những triệu chứng phiền hà như sưng đau lợi, tụt lợi, lung lay răng, trồi răng, hôi miệng. Và chất lượng cuộc sống có tương quan nghịch với số răng có túi lợi sâu >5mm. [5]

\section{KẾT LUẬN}

Sâu răng ảnh hưởng gián tiếp đến CLCS của NCT qua hậu quả mất răng: Điểm OHIP $14 \mathrm{VN}$ nhóm mất rằng: 7,64 điểm (so với nhóm mất răng: 6,92 điểm); OR: 2,42 (CI 95\%: 1,29 - 4,56).

- Viêm quanh răng và tình trạng có dưới 3 vùng lục phân lành mạnh làm giảm CLCS của NCT: Điểm OHIP 14VN nhóm NCT bi VQR là 8,15 điểm (so với nhóm không bị VQR 7,35 điểm); $\mathrm{OR}$ 1,52 (CI 95\%: 1,1-2,1). Điển OHIP 14VN nhóm có dưới 3 VLPLM là 7,82 điểm (so với 5,28 điểm); OR 2,62 (CI 95\% 1,31-5,24). 


\section{TÀI LIÊU THAM KHẢO}

1. Nguyễn Thị Sen (2015), Thực trạng bệnh sâu răng, nhu cầu điều tri và ành hưởng của bểnh đến chất lượng cuộc sống ở người cao tuổi tỉnh Yên Bái năm 2015. Luận văn thạc sỹ y học, Đại học Y Hà Nôii, 44-57.

2. Nguyễn Thị Châu Thoa, và cs (2012), A Vietnamese version of the 14-item oral health impact profile OHIP-14VN, Journal of Epidemiology, 2, 28-35.

3. Phạm Văn Việt (2004), Nghiên cứu tình trạng, như câu chăm sóc sức khỏe răng miệng và đánh giá kết quả hai năm thực hiện nội dung chăm sóc răng miệng ban đầu ở người cao tuổi tại Hà Nội. Luận án tiến sĩ y học, trường Đai học Y Hà Nội, 64-75.

4. Bernabé E và cs (2010), Periodontal disease and quality of life in British adults, Journal of Clinical Periodontology 37, 968-972.

5. Needleman I và CS (2004), Impact of oral health on the life quality of periodontal patients, Journal of Clinical Periodontology, 31, 454-457.

6. Rodakowska và cs (2014), Quality of life measured by OHIP-14 and GOHAI in elderly people from Bialystok, north-east Poland, BMC Oral Health, 14(106), 1-8.

7. Silva A E R và cs (2013), Oral health-related quality of life and associated factors in Southern Brazilian elderly, Gerodontology, 32, 35-45.

8. Ulinski K B G và cs (2013), Factors Related to Oral Health-Related Quality of Life of Independent Brazilian Elderly, International Journal of Dentistry, 2013, 1-8.

\section{TÌM HIỂU YẾU Tố NGUY Cơ NHIỄM KHUẨN VẾT Mổ TẠI KHOA NGOẠI BÊ̂NH VIỆN ĐỐNG ĐA, HÀ NộI NĂM 2021}

\section{Nguyễn Minh Duyên ${ }^{1}$, Lê Thanh Hải ${ }^{1}$, Nguyễn Thị Phương Thùy ${ }^{1}$, Bùi Kim Cương ${ }^{1}$, Lê Thị Thắm ${ }^{1}$, Trần Tuyết Minh ${ }^{1}$}

\section{TÓM TẮT}

Đặt vấn đề: Nhiễm khuẩn vết mổ (NKVM) vẫn là mối lo ngại toàn cầu cần kiểm soát trong số những nhiếm khuẩn bệnh viện phổ biến. Mục tiêu nghiên cứu tìm hiểu các yếu tố nguy cơ liên quan đến NKVM nhằm đưa ra chiến lược kiểm soát phù hợp. Đối tượng và phương pháp nghiên cứu: Tiến cứu mô tả cắt ngang toàn bộ các người bệnh từ trên 8 tuổi, không phân biệt giới được điều trị phẫu thuât thuộc các chuyên khoa: Tiêu hóa -Tiết niêu - Chấn thương. Hồ sơ bệnh án đầy đủ trong thời gian từ tháng 5 đến tháng 9 tại khoa Ngoai bênh viện Đống Đa, Hà Nội. Số liệu được ghi chép hồ sở mẫu, xử lý bằng phần mềm SPSS. 20.0. Kết quả: Tổng số 138 người bênh đat yêu câuu nghiên cứu, nam chiếm $55,1 \%$, nữ chiếm 44,9\%: Yếu tố nguy cơ gồm: Yếu tố người bênh, yếu tố phẫu thuật, yếu tố môi trường và chăm sóc người bệnh. Trong đó yếu tố người bệnh có: tuổi $>60$ tuổi chiếm 36,2\%. Thừa cân, béo phì chiếm 13,8 \%; Yếu tố phẫu thuật: Có vật liệu thay thế + dẫn lưu chiếm $22,5 \%$ và $60,9 \%$. Thời gian phâu thuật dài: từ 60 đến 120 phút chiếm đa số $(76,8 \%), \geq 120$ phút chiếm $18,1 \%$. Yếu tố môi trường và nhân viên y tế: Phòng mố cấp cứu, phòng mổ liên chuyên khoa chưa thực hiện 1 chiều; Bệnh viện chưa có quy định sử dụng kháng sinh dự phòng; $42 \%$ người bệnh không được tắm khử khuẩn trước mổ; $84,8 \%$ người bệnh không được loại bỏ lông tóc theo qui định. Kết luân và khuyến nghị: Qua những yếu tố nguy cơ phát hiện trong nghiên cứu có thể làm tăng tỷ lệ NKVM, chúng

${ }^{1}$ Bệnh viện Đa khoa Đống Đa, Hà Nội

Chịu trách nhiệm chính: Nguyễn Minh Duyên

Email: drminhduyen@gmail.com

Ngày nhận bài: 27.10.2021

Ngày phản biện khoa học: 21.12.2021

Ngày duyệt bài: 30.12.2021 tôi khuyến nghị bệnh viện cân bổ sung một số qui trình và giám sát về an toàn phẫu thuật, các khoa phòng liên quan và nhân viên cần tuân thủ.

Tứ khóa: Nhiễm khuẩn vết mổ; An toàn phẫu thuật; Yếu tố nguy cơ; Chăm sóc vết mổ.

\section{SUMMARY \\ IDENTIFYING THE RISK FACTORS RELATED TO THE SURGICAL SITE INFECTION AMONG THE PATIENTS HAVE BEEN TREATED IN THE SURGICAL DEPARTMENT OF DONGDA GENERAL HOSPITAL, 2021}

Introduction: Surgical Site Infections (SSI) are still a concern globally to control among common nosocomial infections. The aim of the study is to identify the risk factors related in order to make an appropriate control strategy. Materials and methodologies: A cross-sectional descriptive study of all patients from 8 years of age, regardless of gender, who were surgically treated in specialties: Gastroenterology - Urology - Trauma, medical records were completed during the period from May to September at the Department of Surgery, Dong Da Hospital, Hanoi. The data were collected and processed by SPSS software. 20.0. Results: A total of 138 patients met the study requirements, male $55.1 \%$, female $44.9 \%$; Risk factors include: patients surgical procedures- environmental and patient care. In which, patient factors: age > 60 years old accounted for $36.2 \%$. Overweight and obesity accounted for 13.9\%; Surgical procedures: implant materials + drainage accounted for $22.5 \%$ and $60.9 \%$ respectively. Operation duration: from 60 to 120 minutes accounted for the majority,76.8\%, $\geq 120$ minutes accounted for $18.1 \%$. Environmental factors and medical staff: Emergency operating rooms and others have not been set one-way; prophylactic 